\title{
Proposal for a Special Interest Group in Spirituality and Psychiatry
}

\section{Procedure for establishing a Special Interest Group}

(a) Any member wishing to establish a Special Interest Group shall write to the Registrar with relevant details.

(b) The Registrar shall forward the application to Council.

(c) If Council approves the principle of establishing such a Special Interest Group then it will direct the Registrar to place a notice in the Psychiatric Bulletin, or its equivalent, asking members of the College to write in support of such a Group and expressing willingness to participate in its activities.

(d) If at least 120 members reply to this notice, then Council shall formally approve the establishment of the Special Interest Group.

In accordance with this procedure, Council has approved the establishment of a Special Interest Group in Spirituality and Psychiatry, to facilitate the exchange of ideas on a wide range of topics, including the significance of the major religions which influence the values and beliefs of the society in which we live, also taking into account the spiritual aspirations of individuals who do not identify with any one particular faith and those who hold that spirituality is independent of religion. There will be consideration of specific experiences invested with spiritual meaning, including the meaning of birth, death and near-death, mystical and trance states to distinguish between transformative and pathological states of mind, as well as the exploration of protective factors which sustain individuals in crisis and otherwise contribute to mental health.

Members are invited to write in support of this Group and express willingness to participate in its activities. Interested members should write to the Registrar, care of Miss Sue Duncan at the College. If 120 members reply to this notice, then Council shall formally approve the establishment of this Special Interest Group.

MIKE SHOOTER, Registrar, Royal College of Psychiatrists, 17 Belgrave Square, London SW1X 8PG 